\title{
COMMITMENT TO PATIENT CARE:AN EXPLORATORY STUDY AMONG REGISTERED NURSES IN BOPHUTATSWANA
}

\author{
J.N. Mekwa, L.R. Uys, M.V. Vermaak
}

\begin{abstract}
ABSTRICT:

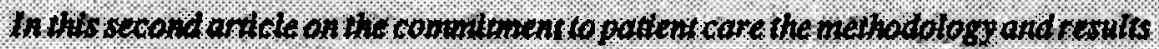

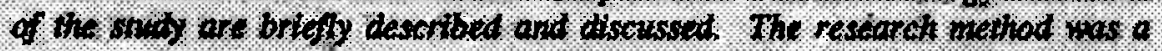

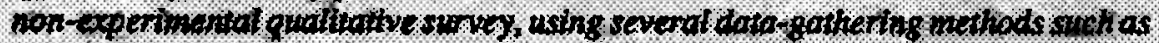

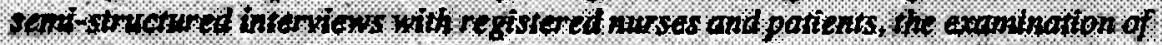

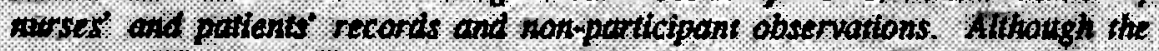

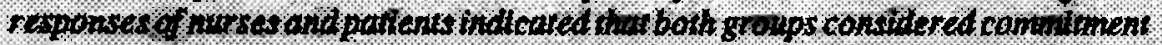

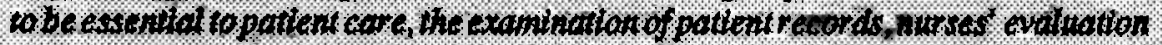

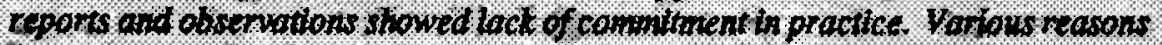
for this are soplorat and recompundations mate.

\section{ONOWHTLE}

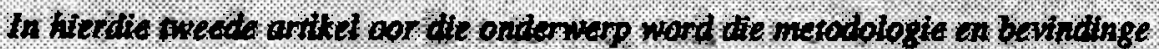

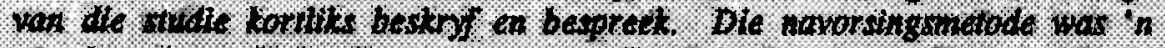

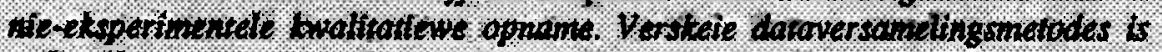

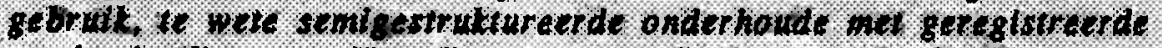

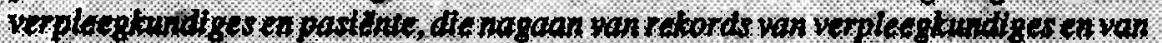

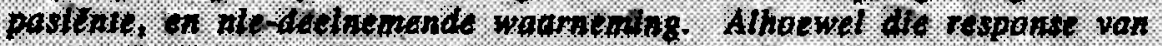

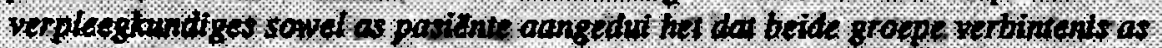

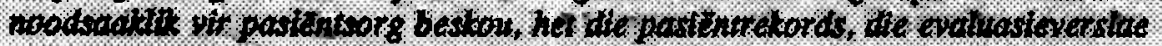

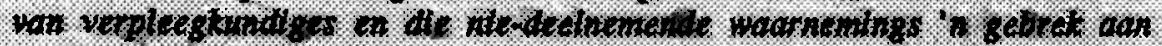

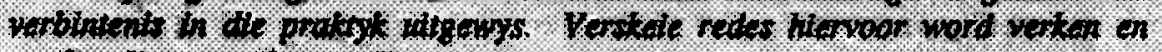

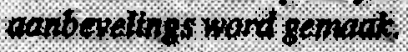

\section{INTRODUCTION}

The theoretical meaning of the concept commitment to patient care was discussed in the previous article. The research into the functional meaning and importance of commitment in the context of the work situation of the registered nurses of Bophutatswana and the identification of factors/behaviours that manifest the nurses' commitment to patient care are the theme of this article.

\section{METHOD}

The following data collection methods were used in this non-experimental qualitative survey:

- Literature survey and concept analysis to establish the meaning of the concept. (Discussed in the previous article)

- Semi-structured interviews with registered nurses and patients.

- Observations at nurses' report giving sessions.

- Examination of nurses' merit reports.

- Examination of ward reports of patients' progress

- Non-participant observations made by the researcher.

Permission was obtained to gather data in a number of hospitals in Bophutatswana and the researcher (J.M.) collected all the data alone to ensure consistency. She introduced herself and explained the purpose of her visit to all staff on duty every time she visited a ward, and always wore a white nurse's uniform with the prescribed distinguishing devices. Tape-recording was used for interviews except in cases where the respondents indicated uneasiness. In these cases the patients who were interviewed agreed to the researcher's writing out their responses, while a number of nurses preferred to write out their own. Some nurses who worked together and some patients insisted on being interviewed in groups and all these preferences were accommodated.

\section{DATA GATHERING}

Interviews

\section{Sampling}

The population for the study consisted of 1,226 registered nurses working in Government health care services in Bophutatswana. Theoretical sampling as described by Melia (1982) and based on the works of Glaser and Strauss (1967); and those of Schatzman, Anselm and Strauss (1973) was used. This entails "the process of data collection whereby the analyst jointly collects, codes and analyzes his data and decides what data to collect next and where to find them, in order to develop his theory as it emerges" (Glaser and Strauss 1967:45). "It is shaped by the time the researcher has available to him, by his framework, by his starting and developing interests, and by any restrictions placed upon his observation by his hosts" (Schatzman, Anselm and Strauss, 1973:38-39). Since a theoretical sample is not numerically predetermined, the number of categories to be worked through was not prescribed but was based upon saturation of categories. Data were collected only and for as long as they were adding to the development of a particular category, after which the category was deemed to be saturated.

A total of 51 registered nurses were interviewed at random in their working situations, first in one hospital, and when the researcher was satisfied that no new data were emerging, the sample was broadened to include two other hospitals.

The sample consisted of nurses working in medical, surgical, paediatric and intensive care wards, community clinics and administration units. This was in accordance with the selection procedure of comparison 
groups for theoretical sampling as outlined by Glaser and Strauss (1967). Also interviewed were a total of thirteen patients randomly selected in two medical wards. Their hospital stay ranged from 12 to 92 days.

\section{Format}

Interviews with nurses were commenced by asking the respondents to tell the researcher about the most significant pleasant and unpleasant experiences they had had which manifested the presence or absence of commitment in relation to patient care. This approach was used as it emerged that the respondents found it easier to express their perceptions if they used examples from their past experiences instead of talking in abstract terms. Further responses were elicited by probing questions and more questions from answers given or statements made by the respondents. The interviews continued for as long as new thoughts were raised.

\section{Patient interviews}

It was decided to interview patients to obtain their care expectations of nurses. The researcher took particular care to make the purpose of the interview quite clear and to dismiss any fears and suspicions that could arise as a result of uncertainty and misunderstandings.

\section{Observations}

\section{Change of shifi reports}

Six change of shift reports at the patients' bedsides were attended in randomly selected wards. The assumption was that the registered nurses would directly or indirectly manifest behaviour significant to the study while giving and receiving report about their patients' progress.

\section{Non-participant observations}

The researcher spent five and three hours respectively in two randomly selected wards, namely a female surgical and an intensive care ward. In the female surgical ward the researcher assumed that in spite of the fact that the registered nurses functioned in a supervisory capacity and that the student nurses and sub-categories performed most of the basic care, certain conclusions relevant to the study could be drawn from the registered nurses' supervisory behaviour.

The assumption in the intensive care ward was that the small number of critically ill patients would allow more observable expressions of affect towards the patient by the registered nurses.

\section{Examination of reports}

A total of 127 merit reports and quarterly reports were examined. Merit reports are summaries of quarterly reports and both are obligatory in terms of the Bophutatswana
Public Service Commision regulations.

This exercise was undertaken with the assumption that the reports would focus on the employees' work behaviour which would be patient care related. It was also assumed that there would be references to behaviour based on nursing values, including commitment.

Statements in the reports were sorted according to whether they indicated positive or negative professional behaviour.

\section{Patients' progress reports}

Twenty-five patients' progress reports were examined. They were chosen at random in the wards in which observations were made and/or interviews were conducted. The reports were assessed for content that reflected some affective notions based on the nurses" professional behaviour towards the patients.

DATA ANALYSIS of interviews with regdstered nurses and their merit reports.

All positive merit reports were considered and handled along with interview responses in analysing data.

Semantic content analysis was done according to the guidelines suggested by Fox (1982). Fox describes semantic content analysis as a process that involves the development of a set of categories intended to represent the dimensions and specifics of the actual content of the responses. Accordingly, from the responses noted, statements whose content was directly related to the subject under study were identified. A total of 219 verbatim statements were listed. These were categorized into nine major groups on the basis of general themes of their content. The groups were then numbered consecutively from $1-9$, and using descriptive terms, each general theme was analysed into sub-groups to accommodate the actual content of the responses. Titles used for both major and sub-groups were worked out from the content of the various groups of responses. The third level of analysis was determined by the actual words, statements or phrases contained in the responses. The selection of these depended on whether the content of such an item was specific enough to convey a complete, meaningful unit of thought in respect of the purposes of the study.

Examination of responses for relevant content was done in the order in which the responses followed one another in the notes made. As each item was identified it was allocated to its sub-group and coded at the same time. It was possible for the content of a single response to be divided into more than one category within a particular major theme or sub-group. Similarly it was possible for a specific item to appear in more than one response.

TABLE ILLUSTRATING SEMANTIC CONTENT ANALYSIS OF RESPONSES - LEGEND OF CODING

\begin{tabular}{|c|c|}
\hline Theme & Subgroup \\
\hline 1. Nature of Commitment & $\begin{array}{l}\text { 1. What it is } \\
\text { 2. Characteristics } \\
\text { 3. Effects }\end{array}$ \\
\hline 2. Commitment Development & $\begin{array}{l}\text { 1. Own attributes } \\
\text { 2. Extrinsic factors }\end{array}$ \\
\hline $\begin{array}{l}\text { 3. Behaviours associated with } \\
\text { commitment to patient care }\end{array}$ & $\begin{array}{l}\text { 1. Relationship with patients } \\
\text { 2. Personal qualities } \\
\text { 3. Care-related behaviour } \\
\text { 4. Quality of performance } \\
\text { 5. Work attitude } \\
\text { 6. Personal experience }\end{array}$ \\
\hline $\begin{array}{l}\text { 4. Need for commitment in } \\
\text { patient care situations }\end{array}$ & $\begin{array}{l}\text { 1. Patient considerations } \\
\text { 2. Performance considerations } \\
\text { 3. Professional considerations }\end{array}$ \\
\hline $\begin{array}{l}\text { 5. Desirable patient-care } \\
\text { environment }\end{array}$ & $\begin{array}{l}\text { 1. Pationt considerations } \\
\text { 2. Nurse's role expectations }\end{array}$ \\
\hline 6. Hindrances to commitment & $\begin{array}{l}\text { 1. Personal factors } \\
\text { 2. Professionally negative behaviour on the } \\
\text { part of the registered nurse } \\
\text { 3. Socio-cultural factors } \\
\text { 4. Management flaws } \\
\text { 5. Education programme problems } \\
\text { 6. Pationt related factors }\end{array}$ \\
\hline 7. Emotion-based expressions & $\begin{array}{l}\text { 1. Ward/Nursing area related } \\
\text { 2. Task related } \\
\text { 3. Patient directed } \\
\text { 4. Non-task related patient directed } \\
\text { 5. Self directod }\end{array}$ \\
\hline 8. lssues causing concem & $\begin{array}{l}\text { 1. Approach to patient care } \\
\text { 2. Recruitment } \\
\text { 3. Attitude towards patient care }\end{array}$ \\
\hline 9. Meaning of commitment & 1. Charactoristics \\
\hline
\end{tabular}


Since one of the purposes of this study was to assess the views of registered nurses regarding the importance of commitment to patient care, the responses were also analysed for quality. This meant indicating whether they were positive, negative, neutral, mixed or ambiguous.

\section{RESULTS}

\section{Interviews with regtstered nurses}

The analysis of interviews with registered nurses showed, among other things, that all responses were in favour of commitment to patient care. In fact, commitment was regarded as essential to patient care, nine reasons being given for this view. Four of these related to the patient, two to performance and three to the profession. A few examples are:

"if you are not committed it means one may cause harm to the patient", "because one has to be conscientious of work" and "nursing is a self-giving profession intended to meet the needs of the client no matter what".

\section{Interviews with patients}

Patients were generally not very keen to discuss their opinion of nurses and the type of care they received as they considered their admission to hospital a privilege that had to be appreciated no matter what.

In response to the question inquiring what was regarded as the ultimate in patient care one patient summed it up by saying "It consists of the nurse putting her spirit in mine and me putting mine in hers. Cure ('Kalafi' a Setswana word meaning 'cure') is more than the administration of medicines. Kalafi ke botho ba motho". (Cure is the humaneness of man).

\section{Observations}

Observations of report rounds could be summarized as follows:

- On the whole little attention was given to the patients as individuals and in one ward only one patient out of 32 was greeted and asked about her progress.

- Great attention was given to the technical correctness of reports and correct use of technical terms, and students were questioned to assess their theoretical knowledge.

The reports were found to be cold and noncommittal in respect of the interaction between the nurse and the patient who was made to be a passive participant.

\section{Observations of ward activities}

- The registered nurses spent most of their time checking records for their technical correctness, and to see whether the prescribed treatment was correctly entered.

They also took blood specimens if nobody else was available for this task. Actual nursing care was given by the sub-categories of nursing staff.

- Except for their being required to assess learners' performance of psycho-motor skills, registered nurses seemed uncertain what their role in regard to patient care entailed.

- There was a general lack of sensitivity to patients' emotional needs, even when these needs were most obvious.

\section{Merit reports}

Most of the statements did not tell much about the quality or professional attributes of the person about whom they were written. In a large number of reports attributes assessed did not relate to patient care, e.g. "He is a good speaker and well able to communicate". However, some reports did recognize the quality of care rendered, particularly in the case of two individuals who had been identified by their colleagues as being committed. This showed consistency of judgment by peers and supervisors and indicated awareness of the need for quality care by those who wrote them.

\section{DISCUSSION}

Selected factors found to influence commitment to patient care are discussed briefly.

\section{The registered nurse as a role model}

The general disregard of patients as significant participants in matters involving their care and the limited amount of time the registered nurses were seen spending at their patients' bedsides (except in the intensive care ward), seemed to be in direct contrast to the profession's theoretical teachings and to the statements made by the nurses during the interviews.

\section{Self-discipline}

Statements euch as "my commitment in nursing has been something that has ruled me" and "one cannot run away from commitment" imply the ability to transcend oneself which can only be attained through professional maturity. Frankl (1978:35) submits that "by forgetting himself and giving himself, overlooking himself, and focusing outward" man achieves self-fulfilment and self-actualization. A committed nurse is therefore mature, self-disciplined and self-actualized.

\section{Professional knowledge}

Respondents agreed that knowledge and understanding of facts are necessary for commitment. The development of professional knowledge requires a considerable amount of intellectual ability. Decisions that may affect the life of the patients in her care must be intelligently arrived at. If this is true then intelligence is essential for commitment.

\section{Values}

If, as suggested by registered nurses, commitment is a value, and since values can be learned (Czmowski 1974: 194), i.e. transmitted to the learner through the process of education, it is within every nurse's reach to develop commitment. According to Czmowski, values arise out of personal experiences, they are personal beliefs "about the worth, desirability, goodness, truth and beauty of a particular idea, object or behaviour". He states further (p.195): "The process of value formation involves an intellectual process directed towards the evaluation of available alternatives, the consequences of the alternatives and a rational choice of one alternative".

\section{Faith}

Statements such as "Christ is the One that gives it" and "It's born out of my dedication to the Lord" were suggestive of the role played by Christianity in commitment development.

\section{The identification of commitment in a nurse}

From the data collected the following areas of behaviour that could be used to determine the presence of commitment in registered nurses were identified:

- the type of relationship displayed towards the patient;

- the amount of energy expended on patient care;

- the degree to which the registered nurse goes out of her way to ensure the welfare of the patient;

- what the registered nurse verbalizes about patient care.

\section{Hindrances to commitment}

In view of the fact that all the respondents made positive statements about the need for commitment to patient care but that little evidence of such commitment was observed, there must be factors that hinder or prevent its development. A few of those identified are discussed.

\section{Management flaws}

These constituted the majority of problems, and merit reports were a particular source of discontent among the registered nurses. They felt that if committed behaviour was not actively encouraged through obvious 
instruments such as professional reports, the chances of its being developed would be reduced. The format used for the reports is designed to channel the writer in a direction which has almost nothing to do with patient care or its quality.

\section{Past experiences and cultural influence}

Negative experiences cited by nurses had no direct bearing on their patients and could have been prevented, for instance, the high-handed attitude of a sister in charge of a ward towards her staff. Cultural background which influences attitudes was found to be a significant factor in the acceptance of certain pacient care responsibilities. An example is a male nurse who said "I do not like general nursing ... it compels me to deal with things I don't enjoy, like nursing a female patient". This could have an effect on the development of commitment.

\section{Poor socialization of student nurses}

The discrepancy between the amount of attention given to direct patient care and paper work by registered nurses was found to be a contributory factory to the poor patient care observed. Purthermore, the manner in which patients' reports, both written and oral, were given, did little or nothing to promote awareness of the need to maintain the individuality of patients. They could therefore not be used to distinguish between nursea capable of rendering quality care and those who could not. The complete reliance on information obtained from written reports as against that which might have been directly obtained from patients illustrates the unhealthy distance that the nurses kept between themselves and their patients. Since Czmowski (1974) suggests that nursing students learn professional values through interaction with their environment, it may be assumed that these practices do little to develop their respect for patients as human beings or to a positive influence on the development of commitment by students.

\section{Job dissatisfaction}

Low morale leading to poor performance was allegedly caused by, among others, the following:

- administrative irregularities leading to unacceptable leadership as seen, for example, in unclear criteria for promotion, indiscreet bureaucracy, a blanket approach to individuals' problems, poor interpersonal relationships and a disregard for nurses' social needs by employers and management.

A senior sister expressed concern at the prospect of being moved away from direct patient care to some office if she were to be promoted. It was apparent from her comment that this very common practice contributed, albeit unintentionally, to poor quality patient care.

\section{Passing the buck}

Registered nurses levelled a great deal of criticism at student nurses for the shortcomings in care situations and seemed not to be aware of their own contribution to the problems related to poor patient care and lack of commitment.

\section{RECOMMENDATIONS}

Since commitment to patient care arises from internalized values, it is recommended that the process of internalization of professional values be initiated early in the programmes for the preparation of registered nurses.

Teachers of nursing, in the classroom as well as the clinical situation, must consciously make efforts to stimulate committed patient care behaviour in students by example and formal teaching. Registered nurses in the clinical setting must be seen to be willing to participate physically in rendering patient care.

Student nurses must be made aware of the place of science in patient care vis-d-vis the quality of care and must be made to understand why the two must be merged to complement each other instead of being seen as parallel entities. The use of terms such as "routine care" must be rooted out of the profession's vocabulary. If nursing is a science as alleged, it must be borne in mind that scientific actions are based on valid grounds and not on routine.

If teaching is part of the registered nurse's responsibility then opportunities for teaching must be created, and teaching by example is a far more effective way of developing affective behaviour in leamers than other methods.

A change of format for merit reports is recommended. If the purpose of merit reports is to identify persons who give quality care, and if promotion in rank is a form of reward for such persons, then the merit report must reflect this quality in no uncertain terms. The uncertainty of those in authority about valid grounds for promotion, which has led to the shifting of the emphasis onto false values, has led to so-called certificate-chasing among nurses and the subsequent decline in the quality of care. A realistic balance needs to be established.

A further recommendation is that registered nurses be prepared in conflict resolution skills and the process of negotiation. Many nurse leaders find criticism threatening and prefer to use unacceptable techniques to silence those who dare to identify irregularities in their leadership. In their attempt to cope with their discontent subordinates resort to professionally unsound defence tactics, which more often than not fail to resolve the conflict. If commitment is the essence of patient care, then it is the responsibility of the whole nursing fraternity, young and old, to promote it at all costs.
This article was derived from a dissertation for the M.Soc.Sc.(Nursing) degree at the University of the Orange State in 1990.

\section{REFERENCES}

Czomowski, M. (1974). Value teaching in nursing, Nursing Fonum, Vol.xiii, No. 2 192-206.

Fox, D.J. (1982). Fundamentals of research in nursing, Norwalk, Appleton-CenturyCrofts, 4th ed.

Frankl, V.E. (1978). The unheard cry for meaning: psychotherapy and humanism. New York: Simon and Schuster.

Glaser, B. and Strauss, A.L. (1967). The discovery of grounded theory: strategies for qualitative research. Chicago: Aldine.

Melia, K.M. (1982). Tell it as it is qualtitative methodology and nursing research: understanding the student nurse's world. Joumal of Advanced Nursing, Vol.7: 327-335.

Schatzman, L. Anselm and Strauss, A.L. (1973). Field research - strategies for a natural sociology: Englewood Cliffs. Prentice Hall Inc.

JN. Mekwa
M.Soc Sc (NursingXU.OF S)
Lecturer, Department of Nursing
University of Bophuthatswans
LR. Uys, DSoc.Sc. (Nursing) U.OF.S)
Professor and Head, Department of Nursing
University of Natal
M.V.Vermaak, M Soc.Sc. (Nursing XU.O.F.S)
Senior lecturer, Department of Nursing
University of the Orange Free State

